\title{
A máquina do psiquismo
}

\author{
Paulo Eduardo Viana Vidal \\ Universidade Federal Fluminense
}

\begin{abstract}
Resumo
A invenção da psicanálise por Freud ocorreu num campo do saber estruturado pelo cientificismo, a crença que investe a ciência do poder de abarcar todos os domínios do real. Segundo autores, este ponto de partida cientificista fragilizaria epistemologicamente o discurso freudiano, o qual se veria assolado por uma insuperável contradição entre um programa mecanicista (baseado em conceitos tais como determinismo, energia, etc.) e uma hermenêutica infinitamente aberta à produção subjetiva de sentido. Focalizando particularmente o "Projeto para uma psicologia científica", no qual Freud constrói uma verdadeira máquina do psiquismo, projetando conceitos das ciências naturais no psiquismo, demonstraremos que a originalidade da racionalidade inventada por Freud consiste justamente em ser uma razão limítrofe, de borda, que conjuga e separa sentido e pulsão, desestabilizando as fronteiras entre os saberes estabelecidos. Concluímos, portanto, que não há no discurso freudiano uma contradição que nos forçaria a optar entre a força e o sentido.

Palavras-chave: psicanálise; cientificismo; sujeito; pulsão; sentido
\end{abstract}

\begin{abstract}
The machine of the psychism. Freud's invention of psychoanalysis emerged from a field of knowledge structured by scientism, the creed that empowers science to embrace all reality. For some authors, this scientistic starting point would weaken Freud's discourse epistemologically, which would be overcome by an insuperable contradiction between a mechanist program (based on concepts such as determinism, energy etc.) and a hermeneutics that is infinitely open to the subject's production of meaning. Focusing especially the "Project for a scientific psychology", in which Freud projects concepts of natural science in the psyche, in order to build a true psyche machine, we will show that the originality of the rationality invented by Freud consists exactly on being a borderline reason, that conjugates and separates sense from drive, blurring the line between established fields. We have therefore concluded that there is no contradiction in Freud's discourse that would force us to choose between force and sense.
\end{abstract}

Keywords: psychoanalysis; scientism; subject; drive; meaning

$\mathrm{N}$ o ensaio "Freud e a reflexão moral", o filósofo pragmatista Rorty (1999), recentemente falecido, interroga a conhecida imagem freudiana que faz da psicanálise o último capítulo de uma história da ciência moderna como sucessão de golpes na pretensão humana de ocupar o centro do universo, da criação e de si mesmo. Para Rorty, a humilhação maior que Copérnico, Darwin e Freud teriam infligido no narcisismo da humanidade consiste menos nesse descentramento, o qual sempre pode dar lugar a um recentramento, que na promoção de uma imagem de mundo mecânica.

Em que consiste tal mecanização do mundo? Derivada do prolongamento da revolução copernicana por Galileu e Newton, é a representação do universo como infinito, composto de partículas homogêneas cujos movimentos de atração e repulsão se acham determinados precisa e rigorosamente por leis matemáticas universais. Com isto, entrou em colapso a antiga idéia de cosmos enquanto totalidade hierarquizada e fechada, grande cadeia do ser na qual cada ente se moveria para realizar sua finalidade, a qual coincidiria com o próprio Bem. A natureza dos antigos "funciona mais como uma causa final que atrai os seres numa direção particular que como uma causa eficiente que os impele irresistivelmente” (Dupré,1993, p. 26).

Ao devir máquina, o mundo herda uma propriedade definidora de tal classe de seres: as máquinas não possuem centro, finalidade intrínseca, podendo se prestar a usos diversos. Destituído assim de propósito e sentido, o universo criado pela física moderna evidencia "que o mundo no qual os seres humanos viviam não os ensinaria mais nada sobre como eles deveriam viver" (Rorty, 1999, p. 194). Uma vez dito isto por relação ao universo, o que aconteceria se considerássemos a nós mesmos máquinas? Neste caso, diz Rorty, de nada adiantaria sairmos à cata do nosso centro para vivermos felizes: seria melhor 
inventarmos um uso para nós mesmos.

Para o filósofo, Freud procurou interiorizar, aplicar o mecanicismo ao domínio psíquico, empreendimento no qual, aliás, teria sido precedido pelo associacionismo de Hume como mecânica das representações. Embora Rorty não mencione obra alguma de Freud para substanciar sua hipótese, esse intento de mecanização da mente transparece nitidamente no "Projeto para uma psicologia científica” (Freud, 1895/1976c). Pouco depois de endereçar o referido "Projeto" ao amigo Fliess, um Freud exultante com tal resultado de suas pesquisas sobre a causalidade das neuroses lhe escreveu que, finalmente, "tudo pareceu encaixar-se, as engrenagens se entrosaram e tive a impressão de que a coisa passara realmente a ser uma máquina que logo funcionaria sozinha” (Freud, 1986, p. 147).

Que máquina não seja aí apenas uma figura de linguagem gasta e cômoda para designar o modelo do psiquismo construído no "Projeto para uma psicologia científica" fica evidente já na abertura do texto, verdadeiro certificado de adesão ao credo mecanicista:

a finalidade deste projeto é estruturar uma psicologia que seja uma ciência natural, isto é, representar os processos psíquicos como estados quantitativamente determinados de partículas materiais especificáveis, dando assim a esses processos um caráter concreto e inequívoco. Há duas idéias principais em jogo: 1) Aquilo que distingue atividade de repouso deve ser considerado como $Q$, sujeita às leis gerais do movimento. 2) Os neurônios devem ser encarados como partículas materiais. (Freud, 1895/1976c, p. 395)

Fazendo obedecer a princípios puramente mecânicos esses dois postulados (quantidade e neurônio), Freud tenta construir no "Projeto" a variedade mesma das funções psíquicas: percepção, memória, consciência, experiências de satisfação e dor, etc. É um modelo neurológico mecanicista, que pretende explicar o funcionamento da mente humana através das propriedades dos neurônios, das relações destes entre si e com a energia que os atravessa. O psiquismo se torna uma máquina que regula (inibe, transmite, etc.) o fluxo quantitativo aportado pelos estímulos externos e excitações internas, permitindo que atravesse ou não os neurônios.

Contudo, Rorty (1999) nota muito agudamente que não é tanto esse mecanicismo que torna a psicanálise perturbadora, mas a postulação de um inconsciente tão inteligente, engenhoso - capaz de atos falhos, chistes, sintomas elaborados - que "é necessariamente lingüístico” (p. 200). O inconsciente excederia, portanto, a tradição que faz do homem sede de opostos, de um pólo "elevado" (alma, razão) que deve controlar, purificar o pólo "baixo" (o instinto, a paixão, a animalidade). Para a reflexão filosófica, a psicanálise traria desta maneira uma questão original, de cunho ético, mais desconcertante que um novo mecanicismo: a noção de que o sujeito não coincide consigo mesmo, de que se acha irremediavelmente marcado por uma Spaltung, uma divisão subjetiva. Por conseguinte, o relato que tecemos de nossa própria existência não pode ser unificado, forçando-nos ao dever ético de reconhecermos o inconsciente enquanto interlocutor, parceiro conversacional, na expressão cunhada por Rorty, na narrativa, na redescrição que fazemos de nós mesmos.
A experiência analítica consistiria, portanto, numa redescrição do próprio passado sob as condições dessa conversação ampliada, na qual nenhuma das partes pode se identificar com a verdade. Para o filósofo, se tomar pelo único ponto de vista é crer ainda no olhar de deus. Tecido na conversação, o Outro de Rorty não provê garantias da verdade nem regras universais. Em vez do reencontro de uma natureza perdida, que diria o que devemos fazer de nós mesmos, a psicanálise visaria que - máquinas que somos - criemos narrações alternativas de nós mesmos, novos estilos de vida, novas metáforas, usando um vocabulário sempre revisto e ampliado. Neste sentido, uma análise "só se diferencia da leitura de história, de romances ou tratados sobre filosofia moral por ser mais dolorosa, por ter uma maior probabilidade de produzir uma mudança radical e porque requer um parceiro" (Rorty, 1999, p. 203).

Irônica, a redescrição rortyana faz do percurso de Freud um paradoxo: cientificista, adepto da causalidade mecânica, ele nos levou a descobrir que a vida é um romance polifônico, work in progress sem palavra final. A experiência analítica não se limita, entretanto, a uma redescrição, entendida como uma nova narração pelo sujeito de sua existência, esta vai de par com uma mudança na economia das satisfações, na economia libidinal do sujeito. Ora, chama a atenção que Rorty só mencione a energia que circula na máquina freudiana, a libido, para advertir o leitor de que o inconsciente não deve ser entendido como reservatório de libido. Par intelectual e parceiro conversacional, o inconsciente não deve ser rebaixado a "uma massa efervescente de energias instintivas desarticuladas” (Rorty, 1999, p. 199). Como Freud usa expressões semelhantes a essas para caracterizar as propriedades do Es, do Isso da segunda tópica em “O ego e o id” (1923/1976f), se depreende que Rorty privilegia, senão exclusiviza, a primeira tópica, entendida como uma tópica da representação e do recalque.

\section{Entre o sentido e a força}

A bem dizer, a crítica de Rorty (1999) não é propriamente original. Ao descartar a energética freudiana em prol do sentido, Rorty se inscreve numa tradição que denuncia em Freud a tentativa, malograda de antemão, de reunir num mesmo corpus teórico uma doutrina da interpretação com o recurso positivista ao energetismo, resquício do seu cientificismo, entendido como a crença ou culto, de origem iluminista, que dota a ciência positiva do poder de abarcar todos os domínios do real e de conduzir a humanidade no sentido do progresso. Pela influência que exercerá, o ensaio “A concepção freudiana do homem à luz da Antropologia”, de Binswanger (1936/1970), constitui um marco nessa tradição de crítica às anfibologias supostamente geradas pelo cientificismo freudiano. Amigo e correspondente de Freud, esse psiquiatra suíço vinculado à fenomenologia lhe reprovava o projeto de tentar estender ao domínio do "espírito" o programa das ciências naturais, no qual mecanicismo e reducionismo andam de mãos dadas. Em conseqüência, a imagem psicanalítica de homem resvalaria para o homo natura, a idéia de um ser passivamente submetido ao jogo maquínico de forças (subentendido, as pulsões freudianas) que se entrechocam cegamente.

Em contrapartida, para Binswanger o homem não é redutível 
ao natural. Ser fundamentalmente histórico, o homem vive num mundo, numa teia de significações cujo sentido objetiva. Ora, o procedimento da construção científica ignora a historicidade do homem, pois avança justamente ao preço da destruição do sentido, de "reduzir o mundo a um fato desprovido de sentido" (Binswanger, 1936/1970, p. 231). Ao vincular sua obra à ciência, Freud teria incorrido numa unilateralidade que Binswanger almeja remediar reintegrando os achados psicanalíticos num todo que lhes dê sua significação plena, numa antropologia inspirada na analítica existencial delineada por Heidegger em Ser e tempo (1927/1988).

Mesmo aceitando a crítica do mecanicismo freudiano realizada por Binswanger, filósofos como Hyppolite (1971) e Ricoeur (1965) apontarão sua unilateralidade, pois desconhecem que o discurso freudiano compreende outra vertente, aquela de uma pesquisa do sentido, que toma os fenômenos psíquicos como fenômenos significativos. Ao resgatarem em Freud uma hermenêutica que contrabalançaria seu naturalismo, tais autores acabaram, no entanto, plasmando e cristalizando a imagem de uma teoria na qual a pulsão e o sentido coabitariam implausível e impossivelmente, restando a questão de como resolver tal contradição, esse ferro de madeira que fragilizaria epistemologicamente a psicanálise.

Quanto a Freud, parece impermeável a tamanha contradição entre, por um lado, a quantidade, o determinismo cego das forças, cuja natureza somática é objeto das ciências naturais; e, por outro lado, o psíquico, com suas representações e articulação de sentido, cujo campo é aquele das ciências históricas. Pelo contrário, ao longo de sua obra, o fundador da psicanálise ressalta que o sintoma conjuga a uma face significante, de mensagem, uma face de satisfação de uma moção pulsional. A "razão desde Freud" (Lacan, 1957/1998a, p. 496) é, por conseguinte, uma razão limítrofe, de borda, cujo espaço é aquele que reúne e separa o campo da pulsão e o campo do sentido, espaço como vimos impensável para toda uma tradição filosófica. Não é à toa que o complexo de Édipo, operador privilegiado dessa conjunção/ disjunção entre pulsão e linguagem, figura entre os grandes ausentes, juntamente com o ponto de vista econômico, do "Freud e a reflexão moral", de Rorty (1999). O que não deixa de suscitar uma questão para o leitor: o uso que fazemos de nós mesmos, da nossa máquina, não tem para o descobridor do inconsciente uma significação edípica?

\section{Freud, Lacan e a máquina}

Finda aqui a trilha a seguir com Rorty (1999); em Lacan (1954/2000), encontramos uma tematização da máquina mais precisa e fecunda, que nos permitirá seguir caminho. No capítulo desse seminário que ganhou o título de "Freud, Hegel e a máquina”, Lacan postula que a descontinuidade entre Hegel e Freud é marcada pela consideração da máquina. Embora contemporâneo da máquina a vapor, o filósofo não fala em energia, "enquanto que é em torno dessa questão que gira toda a discussão de Freud - energeticamente, o que é o psiquismo?” (1954/2000, p.96).

Segundo Lacan, Hegel identificou o homem com o saber acumulado; um século depois, ele tem para Freud, médico, um corpo. O fundador da psicanálise não foi médico como Esculápio e Maimônides o foram, pois só com o dualismo cartesiano o homem passa a ter um corpo. Frente a este, o médico da modernidade tem

a atitude do senhor que desmonta uma máquina. Pouco importam as declarações de princípio, esta atitude é radical. Foi disto que Freud partiu e era este o seu ideal - estudar a anatomia patológica, a fisiologia anatômica, descobrir para que serve esse pequeno aparelho complicado que se acha encarnado no sistema nervoso. (Lacan, 1954/2000, p. 93)

Ainda segundo Lacan, a máquina seria condição de possibilidade do conceito de energia, noção da qual não dispunha o mundo da Antiguidade. Alicerçado no trabalho escravo, o mestre antigo não precisava pôr em equações quanto o escravo produz, quanto custa sua preservação, etc. Com a invenção da máquina a vapor, que inaugura a revolução industrial moderna, se coloca todavia para o capitalista o problema de calcular a eficiência máxima de um maquinário que se degrada, dissipa energia, realiza menos trabalho com o mesmo combustível etc.

Ramo da física que surge no século XIX, a termodinâmica formulará as leis que dão conta da transformação, conservação e dissipação da energia. Tomando por base a máquina a vapor, que converte calor em energia mecânica, a primeira lei da termodinâmica assevera que um processo físico conserva a energia mesmo quando a transforma. Ou seja, a energia é indestrutível, não é passível de ser criada ou destruída. Quanto à segunda lei, afirma que toda transformação energética implica uma dissipação sem retorno da energia. Prosseguindo com o exemplo da máquina a vapor, esta não transforma em trabalho mecânico toda a energia produzida, uma parte é dissipada, degradada sob a forma de calor, não mais podendo ser aproveitada. Em conseqüência, caso o trabalhador resolva girar a máquina a vapor ao contrário, não conseguirá retornar ao estado inicial.

Em suma, a primeira lei da termodinâmica nos ensina que a energia não é uma substância, mas a cifra, a notação matemática de um princípio de equivalência. Já da segunda lei decorre que uma máquina não funciona sem perda. Como nota Lacan (1954/2000), “quando se executa um trabalho, uma parte (da energia) se dissipa como calor, por exemplo, há perda. É o que se chama entropia” (p. 103). Mais precisamente, a entropia é uma grandeza que, ainda de acordo com a segunda lei da termodinâmica, aumenta inexoravelmente num sistema isolado (que não troca energia nem matéria com o ambiente), atingindo o seu valor máximo quando se extingue todo potencial de executar trabalho. Neste momento, o sistema esgotou sua capacidade de se modificar, atingiu o chamado equilíbrio termodinâmico. Numa ruptura com a mecânica clássica e seus fenômenos reversíveis, a termodinâmica lida, portanto, com processos irreversíveis, submetidos à chamada "flecha do tempo" (Coveney \& Highfield, 1990).

De autoria do cientista alemão Helmholtz (1847), o opúsculo Sobre a conservação da força traz uma das primeiras formulações do princípio de conservação da energia, da sua indestrutibilidade e capacidade de transformação, no quadro de uma ontologia da matéria cujo ponto de partida é “a possibilidade de reduzir 
todas as ações da natureza a forças de atração e repulsão cuja intensidade depende apenas da distância entre os pontos que agem uns sobre os outros (p. 1, tradução nossa).

Qualquer semelhança dessa suposição mecanicista com as idéias de base do "Projeto para uma psicologia científica" (1895/1976c) não é mera coincidência. Considerado por Freud um de seus “ídolos”, Helmholtz fundou juntamente com outros físicos e fisiologistas, entre os quais E. Brücke, professor e mestre de Freud, o movimento científico que levaria seu nome - a Escola de Medicina de Helmholtz -, cujo programa consistia em aplicar ao organismo vivo, postulados físico-químicos (Jones, 1953).

Ora, o "Projeto" visa declaradamente projetar no psiquismo suposições das ciências duras da época de Freud, bem na linha do programa que Binswanger qualificou de reducionista. $\mathrm{O}$ historiador da psicanálise, Andersson (2000) salienta, contudo, que a Escola de Helmholtz fez parte de uma tendência inovadora, a qual reorientou a pesquisa médica da anatomia para a fisiologia, da até então supervalorizada tentativa de localização anatômica das doenças mentais para o estudo das funções do sistema nervoso, pesquisadas por meio da eletrofisiologia. Para o autor, essa nova abordagem teria permitido a Freud desfazer a confusão entre paralisia orgânica e paralisia histérica, distinção que mesmo Charcot se revelou incapaz de fazer, porque ainda se achava preso ao antigo paradigma localizacionista.

De fato, já no artigo “Histeria”, Freud (1888/1976a) prioriza claramente a explicação neurofisiológica sobre a anatômica. Condicionada por uma distribuição diferente das excitações no sistema nervoso, a histeria é

uma neurose no mais amplo sentido da palavra - quer dizer, não só não foram achadas alterações perceptíveis no sistema nervoso, nessa doença, como também não se espera que qualquer refinamento das técnicas de anatomia venha a revelar alguma dessas alterações. A histeria baseia-se total e inteiramente em modificações fisiológicas do sistema nervoso; sua essência deve ser expressa numa fórmula que leve em consideração as condições de excitabilidade do sistema nervoso. (p. 79)

Portanto, foi a adesão de Freud (1893/1976b) ao programa científico de ponta na sua época, a maquinização do organismo, que o levou a correlacionar, no artigo “Alguns pontos para o estudo comparativo das paralisias motoras orgânicas e histéricas”, o sintoma histérico de conversão não mais à anatomia médica, mas a uma anatomia popular, imaginária. No mencionado artigo, Freud escreve que, "na paralisia histérica, a lesão deve ser uma modificação da concepção, da idéia de braço, por exemplo” (p. 236).

É uma crítica direta à suposição por Charcot (1887, citado por Bercherie, 1983) de que se acharia na origem do sintoma histérico uma lesão funcional do sistema nervoso, lesão não verificável pelos meios de observação disponíveis, mas cuja existência o progresso da ciência acabaria por atestar. Por que Charcot aposta suas fichas numa causalidade orgânica ainda a ser verificada? Consideremos um trecho das Leçons sur les maladies du système nerveux (1887, citado por Bercherie, 1983), no qual Charcot formula o problema que lhe suscitam certos sintomas, a catalepsia por exemplo que acomete certas histéricas: "pode este estado ser simulado de maneira a enganar o médico?” (Charcot, 1887, citado por Bercherie, 1983, p. 63). Por meio de experimentos que fazem uso de toda uma aparelhagem tecnocientífica, Charcot chega a demonstrar "na maioria dos casos, a ausência de simulação, a objetividade das perturbações e, portanto, a sua natureza orgânica” (Bercherie, 1983, p. 64).

Nota-se que o ponto de partida de Charcot é a decisão de sustentar a objetividade do sintoma histérico contra qualquer presunção de que tivesse por causa a simulação, a imitação mal-intencionada, a mentira. Numa palavra, de que dependesse desse elemento sempre suspeito de parasitar a cientificidade: a subjetividade. Decisão que certamente o alinha no campo da ciência, a qual supõe no real um saber automático, racional e que, sobretudo, não mente. Para o cientista, o real não mente, pois a mentira supõe uma enunciação - um mentiroso.

Do ponto de vista científico, é primoroso o raciocínio que Freud (1893/1976b) emprega para refutar Charcot. Depois de conceder que as chamadas lesões funcionais podem ainda não terem sido detectadas, argumenta que, caso existam, devem produzir uma sintomatologia idêntica àquela de uma lesão orgânica; caso contrário, fica refutada a hipótese orgânica. Em seguida, Freud demonstra com precisão que as paralisias histéricas não seguem os caminhos do sistema nervoso, mas trilhas determinadas por idéias, representações, pela linguagem, em suma.

A partir daí, se descortina para Freud uma anatomia que só pode ser inferida dos usos da língua, dos ditos de cada sujeito - no sintoma histérico, a força e o sentido se encontram. Mas, como objetivar cientificamente um testemunho sempre equívoco, inconsistente e fluido? Ao reincluir no sintoma aquilo que seu estatuto médico excluía - o sujeito enquanto suposto pela fala que dirige a outrem - Freud reintegrava, portanto, no movimento da sua descoberta um elemento considerado inconveniente pelo discurso da ciência.

O preço dessa reinclusão do sujeito no sintoma é uma tensão permanente no seu discurso entre uma racionalidade científica e uma racionalidade de outro tipo, que se busca, que arduamente se faz, suscitando aliás uma ferrenha oposição da parte dos representantes do saber científico. Depois de ouvir uma palestra de Freud sobre a etiologia da histeria, o eminente psiquiatra vienense Kraft-Ebing alcunhou de "conto de fadas científico" suas hipóteses sobre a função causal da sexualidade e da defesa nesta afecção (Freud, 1986, p. 185).

\section{A máquina e o sujeito}

Essa tensão entre duas racionalidades permeia o problema que se coloca para Freud nos textos que examinamos até agora: que tipo de máquina pode incluir o sujeito? Redigidos de 1888 a 1895, no leque de tempo que se abre pouco depois que Freud retorna de Paris, tais artigos expõem uma concepção traumática das neuroses que generaliza a histeria traumática de Charcot. Porém, definido como um afluxo súbito de estímulos que o psiquismo não consegue descarregar, o trauma não faz do sujeito uma mera superfície de recepção, de inscrição de cargas energéticas? E o sintoma não se torna a resultante (no sentido físico do termo) da ação de forças obedientes a uma causalidade mecânica, linear e objetivável? Por conseguinte, Binswanger não teria razão ao afirmar que o homem para Freud não passa de um 
joguete de forças mecânicas?

Para respondermos melhor a essas questões, consideremos brevemente os dois pólos - máquina e sujeito - que colocamos em oposição: o primeiro será representado pelos efeitos da extensão da máquina ao psiquismo no "Projeto para uma psicologia científica" (1895/1976c); o segundo se destacará da noção freudiana de trauma.

Dispositivo que transforma segundo certas leis uma energia de entrada numa energia de saída, é bem uma máquina que Freud agencia no "Projeto", na tentativa de chegar à "fórmula” que lhe daria a "essência” da histeria, para retomar termos que emprega no trecho acima citado do artigo "Histeria” (1888/1976a). À maneira de uma carga elétrica ou hidráulica, circula, portanto, entre os neurônios do aparelho uma energia que, embora não mensurável, é batizada como $Q$, porque apresenta características quantitativas: pode diminuir, aumentar, se deslocar, converter, ser descarregada, etc.

Nota-se que $Q$ é muito simplesmente a letra para inscrever uma incógnita, uma energia capaz de se deslocar sob a cadeia de representações. A mencionada fórmula da histeria seria, por conseguinte, a notação simbólica que exprimiria a particularidade das relações energéticas na histeria e outras afecções. No "Projeto para uma psicologia científica", Freud aduz que supôs $Q$ em função das suas “observações clinicopatológicas, sobretudo das relativas a idéias excessivamente intensas - na histeria e nas obsessões, nas quais, como veremos, a característica quantitativa surge com mais clareza do que seria normal” (1895/1976c, p. 396).

No exemplo extremamente singelo e sugestivo de Freud, um sujeito chora copiosamente toda vez que chega à sua consciência certa representação superintensa, denominada $A$. Só que o sujeito não entende, acha inclusive absurdo que tal representação, para ele anódina, o faça chorar de tal forma. Tomando por base a lei de conservação da energia, Freud infere que a representação $A$ se tornou superintensa porque lhe foi adicionada uma quantidade subtraída e deslocada da representação $B$, essa sim "traumática”, capaz de causar o choro. Para dar conta do sintoma, Freud põe em jogo, portanto, duas dimensões, às quais denomina, também, representação e montante de afeto. O próprio recalque, que torna inconsciente uma representação, opera separando a representação do seu afeto, tendo assim um sentido quantitativo de subtração. Mas, prosseguindo com a contabilidade, para onde vai o $X$ subtraído? Retirado da representação traumática, se deslocará ao longo da cadeia de representações, se adicionará ao sintoma.

O inconsciente se constitui, portanto, nessa separação entre representação e montante de afeto, ou seja, inconsciente é o nome da hipótese que Freud julga necessária para correlacionar ambos. Mas, qual é a causa do recalque? E qual a natureza do recalcado?

No campo clínico, $Q$ é sempre identificado por Freud no "Projeto" com a sexualidade, por mais que em princípio compreenda estímulos de origens diversas. Por que a sexualidade? Devido ao despertar tardio, pubertário da sexualidade por relação às outras funções humanas, unicamente nesse domínio a rememoração ulterior de um encontro precoce do sujeito com o sexual - tal como a sedução da criança por um adulto - pode conferir à lembrança uma intensidade traumática, maior que na época dos fatos, induzindo assim o seu recalque. Ao ser significada, decifrada na puberdade como sexual, a lembrança infantil da sedução se torna traumática e é recalcada.

Portanto, o recalcado é sexual, embora a recíproca não seja verdadeira: nem todo sexual é recalcado. Há um paradoxo na lógica da operação, para o qual Freud não atenta na época: produto do recalque, a sexualidade é também sua causa. Quanto ao sentido conferido à lembrança traumática, a noção de sedução indica que tem a ver com uma proibição, um interdito social maior. Inferido do discurso das histéricas, o inconsciente se apresenta para Freud no registro da subtração, do menos, pois o recalque, ao tornar inconsciente o significante traumático (uma moção pulsional, para usar a linguagem ulterior de Freud), acarreta uma perda de gozo, transforma o gozo em castração. E, como o significante não recupera de todo o gozo, o inconsciente repete, tentando insistentemente apagar a diferença entre a satisfação obtida e a satisfação buscada, como dirá mais tarde Freud (1920/1976e, p. 60), deixando claro que o inconsciente é uma máquina que trabalha para o gozo.

\section{A máquina e o simbólico}

Fica agora mais claro porque Lacan (1954/2000) afirma, como vimos, que as noções de energia, da sua conservação e perda, dependem da existência da máquina: materialização do simbólico, esta permite a contagem. Transposta por Freud ao psiquismo, vemos que a metáfora da máquina faz surgir o inconsciente como perda, subtração.

Contudo, a máquina não se limita, para Lacan, a uma materialização do simbólico, não se confunde com o mero artefato, tal uma mesa ou um par de sapatos. A máquina encarna antes, na sua pureza, o que Lacan (1954/2000) chama de "a atividade simbólica mais radical no homem" (p. 95). Para entendermos isto, devemos pensar a máquina na sua autonomia por relação ao homem ou ao biológico, supondo assim na sua definição uma ordem, programa ou circuito que se repete.

Ainda no mesmo seminário, Lacan aproxima a noção de circuito da sua idéia de que o inconsciente é o discurso do outro, de uma fala que nos precede e constitui. Exemplifica com o supereu, instância para Freud de uma herança:

este discurso do outro não é o discurso do outro abstrato, do outro na díade, do meu correspondente, nem mesmo simplesmente do meu escravo, é o discurso do circuito no qual me acho integrado. Eu sou um de seus elos. É o discurso do meu pai, por exemplo, na medida em que meu pai cometeu faltas que eu sou absolutamente condenado a reproduzir - é o que se chama super-ego. (Lacan, 1954/2000, p. 112)

Por conseguinte, descentrada, automática, repetitiva, a máquina presentificaria com perfeição o poder disruptivo, fragmentador, mortífero que a linguagem exerce sobre o humano. Não seria isto que Freud (1895/1976c) procura ficcionar no "Projeto para uma psicologia científica"? De fato, o texto inicia pela ficção de um aparelho psíquico que, regido pelo princípio chamado de inércia, tenderia antes de tudo a se desfazer dos estímulos. Antiadaptativo, antihomeostático, antivital, o princípio de inércia invalida a existência de aparelho psíquico, sujeito ou Outro. 
Contudo, as exigências da vida (as necessidades) se conjugam com a impotência, o desamparo originário da criança, para que o apelo ao Outro tenha início, apelo cuja forma primordial é o grito. Pois apenas o cuidado alheio pode minorar o estímulo, provocando na criança uma experiência que é de satisfação. Para Freud, tal experiência de satisfação provoca certa percepção do objeto e deixa traços mnésicos (visuais, auditivos, táteis, etc.). Quando a excitação se fizer sentir de novo, uma moção psíquica - que Freud chama desejo - reinvestirá os traços mnésicos para restabelecer, pela via da alucinação, a situação de satisfação primeira.

Veiculado pelo processo primário, o desejo, fome de traços, visa repetitivamente a identidade de percepção, a coincidência da percepção atual com o traço mnésico, o selo da primeira vez. A função primeira do traço de memória freudiano não é, portanto, epistêmica, no sentido de prover o conhecimento capaz de ajustar o organismo ao meio. Pois o processo primário não visa conhecer, mas re-conhecer, reencontrar por meio da identidade de percepção esse outro que a dependência da criança torna primordial. Freud (1986) qualificará de "inesquecível” esse outro primordial ao expor sua nova teoria de que o ataque histérico não é uma mera descarga, mas uma ação, um meio de obtenção de prazer: "todos os ataques de tonteiras e acessos de choro visam a uma outra pessoa - mas, basicamente, visam àquela outra pessoa pré-histórica e inesquecível, que jamais é igualada por ninguém posteriormente (p. 213).

\section{Das Ding}

Num trecho do "Projeto para uma psicologia científica" que Lacan (1959/2001) celebrizou, Freud (1895/1976c) tematiza como o outro se desdobra nessa “outra pessoa” além dele mesmo, “pré-histórica e inesquecível”, numa dimensão nostálgica. Segundo Freud, quando o objeto da percepção é outro ser humano, um semelhante, o complexo perceptivo que dele emana se divide em duas partes: a primeira engloba tudo que do objeto pode ser formulado a título de atributos, qualidades, os quais o sujeito compreende, re-conhece graças às informações que possui, à experiência que tem do próprio corpo; a segunda parte consiste numa estrutura constante estrangeira, não compreensível e inassimilável, Outro absoluto do sujeito que Freud denomina das Ding, (a Coisa).

É uma oposição entre o que se pode dizer e o que não se pode dizer do objeto, oposição que Lacan (1959/2001) faz corresponder à distinção existente na língua alemã entre Sache e Ding, dois vocábulos que querem dizer coisa, mas cujos empregos são diversos: Sache significa o produto da ação humana enquanto governada pela linguagem, ao passo que Ding refere a coisa da ação humana não de todo governada pela linguagem.

No interior mesmo da representação, Freud introduz, portanto, uma clivagem entre predicável (suporte de atributos) e impredicável, aquilo que não se presta a nenhum juízo: a Coisa, na falta de qualquer outro nome. Deixando de ser um objeto do mundo, a Coisa, reposta na intimidade do sujeito, o torna estrangeiro para si mesmo. Para Lacan, o momento paradigmático dessa clivagem aparece no "Projeto" como a transformação do grito da criança em apelo ao Outro: ao interpretar o grito como demanda, o Outro lhe atribui um significante, significa que há ali um sujeito, mas no mesmo movimento separa a criança do grito, pois a faz entrar numa articulação discursiva.

Portanto, no descompasso, na hiância entre as exigências da vida e o desamparo da criança se instala uma estrutura significante, por cujas redes e circuitos o desejo circulará: sem substância, vazio no cerne das representações, a Coisa inalcançável é a sua mola propulsora. A metáfora da máquina serve a Freud para conceituar a memória que chamou de inconsciente num registro que transcende a relação inter-humana e o domínio biológico.

Todavia, salta aos olhos que é bem singular a máquina do "Projeto": funciona desfuncionando, repetindo os fracassos, não tem uma boa curva de aprendizagem. Além disto, a Coisa introduz na máquina uma causalidade não mecânica, não linear: a causalidade de uma ausência que afeta todo termo inscrito, presente. Poeta que tentou igualar em tudo cada palavra ao silêncio que só afetava o objeto, Mallarmé (1970) fez da Coisa seu programa: "Evocar numa sombra expressamente o objeto calado por palavras alusivas jamais diretas, se reduzindo a silêncio igual” (p. 302).

\section{Para concluir}

Em “De nossos antecedentes”, Lacan (1966/1998b) caracteriza seu retorno a Freud como "a retomada pelo avesso do projeto freudiano" (p. 68), frase na qual o termo projeto designa também o "Projeto para uma psicologia científica" (Freud, 1895/1976c). Tal retorno, que não objetiva voltar ao ponto inicial, mas percorrer o caminho que leva ao novo pela via da repetição, certamente não obedece a uma epistemologia descontinuista, do corte, para a qual o "Projeto" seria prépsicanalítico. Afinal, por que ainda estudar um escrito sobre neurônios que tem uma concepção rudimentar do inconsciente, sequer fala em pai, Édipo, etc.?

Não obstante, vimos que Lacan extraiu do "Projeto" a Coisa, termo heterogêneo à significação, aos objetos do mundo e à objetividade científica. Com a noção de objeto a, Lacan tornará das Ding operacional em psicanálise: resto produzido pela articulação significante, o objeto a condensaria o gozo perdido pelo sujeito ao entrar na linguagem e causaria o desejo. Assim procedendo, lembra Cottet (1996), a psicanálise "retoma os rebutalhos da ciência e o que é forcluído do seu discurso, a relação do desejo com um objeto por natureza não desejável” (p. X). Ao cavar uma brecha entre a legalidade estrita dos fenômenos científicos e a causalidade da Coisa, o "Projeto" abre uma margem de indeterminação - o espaço do sujeito.

Demarquemos agora os limites do "Projeto”, aproveitando uma sentença de Lacan (1954/2000) no seminário dois: “máquina é a estrutura enquanto destacada da atividade do sujeito. O mundo simbólico é o mundo da máquina” (p. 63). Por mais que esta obra antecipe como vimos inúmeros conceitos que se tornarão centrais em Freud (objeto perdido, recalque, desejo, etc.), as respostas que traz quanto à atividade do sujeito derivam ainda de um momento, bastante sofisticado é verdade, da noção freudiana de trauma: o trauma a posteriori ou póstumo.

De origem mecânica, a noção de trauma denotava 
originalmente um choque de corpos. Transposta para a subjetividade, dramatiza para Freud, nos "Estudos sobre a histeria” (1895/1976d), o impacto, a comoção provocada por incidentes reais: a morte súbita de entes queridos, no caso de Emmy von N., a agressão sexual que Katharina sofre da parte do tio, etc. De valor traumático, por assim dizer, universalmente válido, tais infortúnios apresentam o sujeito do trauma de modo passivo, como uma superfície de inscrição submetida a uma causalidade linear e objetivável. O sintoma representa o trauma, não o sujeito. Há certamente uma participação do sujeito, que se defende afastando da consciência essas cenas, resiste à sua rememoração, mas Freud não articula a defesa com o desejo. A cura pela abreação não é uma realização do desejo.

Mais sofisticada, a noção de trauma no "Projeto" confere até mesmo um novo peso à realidade psíquica ao radicar o traumático na lembrança do fato e não no fato enquanto tal. Todavia, o conceito de a posteriori ainda coincide aí com o efeito retardado, diferido de uma significação (sexual) em potência, latente, que é finalmente ativada. Ora, a sexualidade não interessa a Freud como uma substância opaca, uma energia que circularia numa máquina, o que faria dele um precursor da sexologia ou da terapia reichiana. O que a psicanálise traz de original são perguntas de outra ordem: como pode subjetivar, dar conta da sexualidade um sujeito? Que saber um sujeito pode mobilizar, elaborar para significar a ausência da Coisa, perda que a máquina, a estrutura de entrada lhe impõe? Pois há experiência analítica apenas quando opera a união na diferença desses termos heterogêneos: sujeito e Coisa, sentido e pulsão.

Questões que despontam, portanto, dessa charneira entre o campo do sentido e o campo da pulsão que Freud inventou, apresentando assim para a filosofia e para a cultura um convidado incômodo, estranho ao sentido - a pulsão - ao mesmo tempo em que interroga a ciência quanto ao estatuto que confere ao sujeito.

\section{Referências}

Andersson, O. (2000). Freud precursor de Freud. São Paulo: Casa do Psicólogo.

Bercherie, P. (1983). Genèse des Concepts Freudiens. Paris: Navarin.

Binswanger, L. (1970). La conception freudienne de l'homme à la lumière de l'anthropologie. In Disscours, parcours et Freud. Paris: Gallimard. (Texto original publicado em 1936)

Cottet, S. (1996). Freud et le désir du psychanalyste. Paris: Seuil.

Coveney, P., \& Highfield, R. (1990). The arrow of time. Londres: Flamingo.

Dupré, L. (1993). Passage to Modernity. New Haven: Yale University Press.

Freud, S. (1976a). Histeria. In Edição standard brasileira das obras psicológicas completas de Sigmund Freud (Vol. 1, pp. 79-101). Rio de Janeiro: Imago. (Texto original publicado em 1888)

Freud, S. (1976b). Alguns pontos para o estudo comparativo das paralisias motoras orgânicas e histéricas. In Edição standard brasileira das obras psicológicas completas de Sigmund Freud (Vol. 1, pp. 223-242). Rio de Janeiro: Imago. (Texto original publicado em 1893)

Freud, S. (1976c). Projeto para uma psicologia científica. In Edição standard brasileira das obras psicológicas completas de Sigmund Freud (Vol. 1, pp. 381-511). Rio de Janeiro: Imago. (Texto original publicado em 1895)

Freud, S. (1976d). Estudos sobre a histeria. In Edição standard brasileira das obras psicológicas completas de Sigmund Freud (Vol. 2, pp. 381-511). Rio de Janeiro: Imago. (Texto original publicado em 1895)

Freud, S. (1976e). Além do princípio de prazer. In Edição standard brasileira das obras psicológicas completas de Sigmund Freud (Vol. 18, pp. 17-90). Rio de Janeiro: Imago. (Texto original publicado em 1920)

Freud, S. (1976f). O ego e o id. In Edição standard brasileira das obras psicológicas completas de Sigmund Freud (Vol. 19, pp. 23-284). Rio de Janeiro: Imago. (Texto original publicado em 1923)

Freud, S. (1986). A correspondência completa de Sigmund Freud para Wilhelm Fliess 1887-1904. Rio de Janeiro: Imago.

Heidegger, M. (1988). Ser e tempo. Rio de Janeiro: Vozes. (Texto original publicado em 1927)

Helmholtz, H. (1847). Uber die Erhaltung der Kraft. Berlim: Druck und Verlag.

Hyppolite, J. (1971). Ensaios de psicanálise e filosofia. Rio de Janeiro: Taurus.

Jones, E. (1953). The life and work of Sigmund Freud. Nova York: Basic Books.

Lacan, J. (1998a). A instância da letra no inconsciente ou a razão desde Freud. In Escritos (V. Ribeiro, Trad., pp. 496-533). Rio de Janeiro: Jorge Zahar. (Texto original publicado em 1957)

Lacan, J. (1998b). De nossos antecedentes. In Escritos (V. Ribeiro, Trad., pp. 6976). Rio de Janeiro: Jorge Zahar. (Texto original publicado em 1966)

Lacan, J. (2000). O seminário: livro 2. O eu na teoria de Freud e na técnica da psicanálise. Rio de Janeiro: Jorge Zahar. (Texto original publicado em 1954)

Lacan, J. (2001). O seminário: livro 7. A ética da psicanálise. Rio de Janeiro: Jorge Zahar. (Texto original publicado em 1959)

Mallarmé, S. (1970). Igitur divagations un coup de dès. Paris: Gallimard.

Ricoeur, P. (1965). De l'interprétation. Paris: Seuil.

Rorty, R. (1999). Freud e a reflexão moral. In Ensaios sobre Heidegger e outros (pp. 193-219). Rio de Janeiro: Relume-Dumará.

Paulo Eduardo Viana Vidal, doutor em teoria psicanalítica pela Universidade Federal do Rio de Janeiro, é professor adjunto da Universidade Federal Fluminense. Endereço para correspondência: Rua Desembargador Cesinio Paiva, 15 (São Francisco); Niterói, RJ; CEP: 24360-530. Tels: (21) 2610-3969 / 9975-3969. Email: pvidal@vm.uff.br 